Revista de Derecho

de la Pontificia Universidad Católica de Valparaíso

XXXI (Valparaíso, Chile, 2 Semestre de 2008)

[pp. 255 - 265]

\title{
LA CULPA COMO ELEMENTO CONSTITUTIVO DEL INCUMPLIMIENTO EN LAS OBLIGACIONES DE MEDIO O DE DILIGENCIA*
}

[Guilt As a Constituing Element of the Non-Compliance with the Obligations of Means and Diligence]

\section{Carlos Pizarro Wilson** \\ Universidad Diego Portales}

\section{RESUMEN}

En este trabajo se pretende demostrar que la noción de incumplimiento de las obligaciones que involucran diligencia comprende la culpa, de la cual no puede disociarse, bastándole al acreedor acreditar la existencia de la obligación y al deudor le corresponde probar la diligencia o cumplimiento, en conformidad a los artículos 1547 inciso 30 CCCh. y 1698 del mismo Código.

Palabras Clave: Responsabilidad contractual - Incumplimiento - Obligaciones de medio - Carga de la prueba - Presunción de culpa.

\section{ABSTRACT}

This work attempts to show that the notion of non-compliance with the obligations entailing diligence covers guilt, from which it cannot become separate. The creditor only has to certify the existence of the obligation and the debtor has to prove the diligence or compliance, according to article 1547, $3^{\text {rd }}$ section of the Chilean Civil Code, and article 1698 thereof.

KEYwORDS: Contractual responsibility - Non-compliance - Obligation of means - Burden of proof-Presumption of guilt.

* Este artículo forma parte del Proyecto Fondecyt Regular No 1085264 "Hacia la construcción de un sistema de remedios por incumplimiento contractual en el Código Civil" en que el autor es coinvestigador.

** Profesor Investigador de la Facultad de Derecho de la Universidad Diego Portales. Doctor en Derecho por la Universidad Paris II (Panthéon-Assas). Dirección postal: Facultad de Derecho, Universidad Diego Portales, Avenida República 105, Santiago, Chile. Correo electrónico: carlos.pizarro@udp.cl 


\section{INTRODUCCIÓN}

Frente al incumplimiento contractual el sistema jurídico provee al acreedor de distintas acciones destinadas a satisfacer su interés defraudado ${ }^{1}$. Se constata por la doctrina una dispersión de los remedios ante el incumplimiento contractual ${ }^{2}$. Existen remedios generales y especiales. Entre los primeros destacan la ejecución forzosa o cumplimiento en naturaleza, la resolución del contrato o la indemnización de los perjuicios. Las acciones especiales pueden derivar de la voluntad de las partes, así ocurre con la resolución unilateral del contrato o pueden estar establecidas en la ley, siendo un ejemplo la acción por vicios ocultos o redhibitorios.

Tratándose de estos diversos remedios frente al incumplimiento contractual, la doctrina reciente se ha esforzado por excluir la culpa como un elemento transversal. La culpa no sería una condición necesaria para el ejercicio de cada remedio en particular. En otros términos, la culpa no correspondería a un elemento constitutivo del incumplimiento. Éste se debería entender como la insatisfacción de la prestación sin análisis del comportamiento del deudor ${ }^{3}$. Ahora, si bien es cierto que el incumplimiento a secas constituye la condición genuina de aplicación de los remedios, con indiferencia de la culpa, en este trabajo se pretende mostrar que tratándose de obligaciones que involucren la diligencia del deudor, la culpa constituye parte de la noción de incumplimiento. Esta constatación es relevante para

${ }^{1}$ Puede consultarse: Barros Bourie, E., Finalidad y alcance de las acciones y los remedios contractuales, en Estudios de Derecho Civil III (Santiago, LegalPublishing, 2008), p. 403; Pizarro Wilson, C., Hacia un sistema de remedios al incumplimiento contractual, en Estudios de Derecho Civil III (Santiago, LegalPublishing, 2008), p. 395.

${ }^{2}$ Peñailillo Arévalo, Daniel, Las obligaciones. Teoría general y clasificaciones. La resolución por incumplimiento (Santiago, Editorial Jurídica de Chile, 2003), pp. 4041; Vidal Olivares, A., La pretensión de cumplimiento especifico y su inserción en el sistema de remedios por incumplimiento en el Código civil, en CORRAL, Hernán- RODRíGUEZ, María Sara (coordinadores), Estudios de Derecho Civil II (Santiago, LexisNexis, 2006). pp. 517 ss.; BARROS BOURIE, E., La diferencia entre estar obligado y ser responsable en el derecho de los contratos, en VARAs Braun, Juan Andrés - Turner SaELzer, Susan (coordinadores), Estudios de Derecho Civil (Santiago, LexisNexis, 2006), pp. 721 ss.

${ }^{3}$ En este sentido en forma paradigmática Vidal Olivares, A., El incumplimiento de obligaciones con objeto fungible y los remedios del acreedor afectado. Una relectura de las disposiciones del Código civil sobre incumplimiento, en GUZMán BRITO, Alejandro (editor científico), El Código Civil de Chile (1855-2005) (Santiago, LexisNexis, 2007), p. 495 ss. En términos más amplios, PizArro Wilson, C., La responsabilidad contractual en derecho civil chileno, MANTILLA, Fabricio (coordinador), Libro colectivo. Problemas de derecho de los contratos (Bogotá, Legis, 2007), pp. 209-223. 
dilucidar la forma en que debe entenderse la regla de presunción de culpa prevista en el artículo 1547 inciso $3^{\circ}$ CCCh., en relación a la regla del artículo 1698 del mismo Código.

$\mathrm{El}$ análisis requiere referirse al incumplimiento y las obligaciones de medios (II) y a la carga de la prueba del incumplimiento de obligaciones de medio (III).

\section{EL INCUMPLIMIENTO Y LAS OBLIGACIONES DE MEDIOS}

El incumplimiento contractual asume tres formas típicas: el incumplimiento total de alguna obligación contractual, el cumplimiento imperfecto, por satisfacción parcial en la ejecución de una o más de las obligaciones y, por último, el cumplimiento tardío, del cual se derivan los daños moratorios.

Para que se verifique responsabilidad contractual, se requiere un incumplimiento, que dicho incumplimiento sea culpable, un daño y la respectiva relación de causalidad. A esto debiera sumarse, tratándose de indemnización por el retardo, la constitución en mora del deudor.

Como indica el profesor Vidal Olivares: "El incumplimiento en su sentido más amplio se confunde con la no realización de la prestación o, en otros términos, con cualquiera desviación del programa o plan ideal de prestación inicialmente acordado por las partes"4. En el mismo sentido, a fin de definir el alcance de la obligación y su objeto, se coloca el acento en el interés del acreedor y la prestación puede entenderse en dos sentidos: “a) como comportamiento efectivo del deudor que se confunde con el propio cumplimiento de la obligación; b) como plan o proyecto ideal contemplado inicialmente por las partes cuando nace la relación obligatoria y que se aspira que sea realidad en un momento posterior"s.

Respecto al incumplimiento de las obligaciones contractuales resulta necesario considerar la clasificación entre obligaciones de medios y de resultado, siendo diversa la exigencia al deudor según se trate de una u otra categoría de obligación.

En las primeras, como se sabe, al deudor se le exige una conducta diligente para que logre la satisfacción de la prestación comprometida. No existe un compromiso con el resultado, el deudor debe ser diligente en el

${ }^{4}$ Vidal Olivares, A., La protección del comprador. Régimen de la Convención de Viena y su contraste con el Código Civil (Valparaíso, Ediciones Universitarias de Valparaíso, 2006), p. 177.

${ }^{5}$ Vidal Olivares, A., La protección del comprador, cit. (n. 4), p. 175, quien sigue a Díez- Picazo, L., Fundamentos de Derecho civil patrimonial. Introducción. Teoría general del contrato y las relaciones obligatorias (Madrid, Civitas, 1996), I-II, p. 236. 
intento por lograr dicho resultado o pretensión a favor del acreedor. En cambio, las obligaciones de resultado exigen al deudor la pretensión misma, sin miramientos a la diligencia que haya comprometido para obtenerla ${ }^{6}$.

Es decir, sólo en las obligaciones de medio el deudor para determinar si cumplió o no, debe realizarse un análisis de su conducta destinada a la satisfacción del interés del acreedor. En este sentido debe entenderse el artículo 1547 CCCh., el cual recoge la denominada prestación de culpas, en conformidad a la cual el deudor responde de culpa leve, levísima o lata, según la utilidad que le reporte el contrato a las partes ${ }^{7}$. Es decir, la regla citada contempla distintos grados de diligencia exigibles al deudor para evaluar si satisfizo o no la obligación comprometida ${ }^{8}$.

${ }^{6}$ Sobre esto la literatura es inmensa, en el derecho francés, fuente de la distinción puede consultarse Demogue, R., Traité des obligations (Paris, Arthur Rousseau, 1923-1933), V, núm. 1237; y VI, núm. 599 ; MORTON, G., Obligations de résultat et obligations de moyens, en Revue Trimestrelle de Droit Civil (1935), p. 499; EsMEIN, P., Remarques sur les nouvelles classifications des obligations, en Mélanges Capitant (Paris, Dalloz, 1939), p. 235; Le fondement de la responsabilité contractuelle, en Revue Trimestrelle de Droit Civil (1933), p. 827; MAZEAUD, H., Essai de classification des obligations, en Revue Trimestrelle de Droit Civil (1936), p. 1 ss.; THOMAs, C., La distinction des obligations de moyen et des obligations de résultat, en Revue Trimestrelle de Droit Civil (1937), p. 636; Tunc, A., La distinction des obligations de résultat et des obligations de diligence, en Juris Claseur Périodique. Doctrine (1945), p. 449 ss.; BeInex, R., La charge de la preuve de l'exécution en matière contractuelle, en Revue Critique (1938), p. 657; Rodière, R., Études sur la dualité des régimes de responsabilité, en Juris Claseur Périodique. Doctrine (1950), p. 861; Frossard, J., La distinction des obligations de moyens et des obligations de résultats (Préface de R. NERSON, Paris, LGDJ., 1965), núm. 179, p. 95.

${ }^{7}$ La razón de introducir la prestación de culpa estaría en la dificultad de interpretación de los comentaristas del Code Civil ante la aparente contradicción de sus artículos 1137 y 1147. Sobre esta tesis Pizarro Wilson, C., Étude critique de la responsabilité contractuelle en droit positif chilien (tesis, Paris II, 2003), p. 101. Para los antecedentes históricos de la exclusión en derecho francés, véanse: BigOTPréAmeneu, F. J., Présentation au corps législatif et exposé des motifs du titre des contrats, en Fenet, Recueil (Paris, 1829), XIII, p. 230; Terré, F. - Simler, Ph. - Lequette, Y., Les obligations (Paris, Dalloz,1996), núm. 572, p. 549; Larroumet, Ch., Droit civil. Les obligations (Paris, Economica, 1998), núm. 650, p. 596; RÉMY, Ph., La responsabilité contractuelle. Histoire d'un faux concept, en Revue Trimestrelle de Droit Civil (1997), p. 328.

${ }^{8}$ Sobre la teoría de prestación de culpas: PотніER, R., Traité des obligations, en Euvres de Pothier por M. Bugnet (1861), II, núm. 142, p. 66; y véase también la defensa del propio Pothier en el "Apéndice" de su tratado, bajo el título "Observation générale sur le précédent traité”. Se trata de una respuesta a LEBRUN, Essai sur la prestation des fautes, también como "Apéndice" al Traité des Obligations, en Euvres de Pothier editadas por Bugnet. Sobre la cuestión en derecho chileno: Claro Solar, L., Ligeras observaciones sobre la prestación de la culpa en el contrato de mandato, en Revista 
La razón primigenia de la clasificación de las obligaciones de medios y de resultado fue resolver una supuesta contradicción entre los artículos 1137 y 1147 del Código Civil francés, aludiendo el primero al buen padre de familia y el segundo se refiere sólo al incumplimiento. Demogue en su célebre Tratado señaló que en el primer artículo se trataba de obligaciones de medio y era el acreedor quien tenía que probar el incumplimiento; en cambio en el segundo, se presumía el incumplimiento culpable, debiendo el deudor probar la diligencia para excluir la responsabilidad ${ }^{9}$.

En definitiva, dicha clasificación venía a resolver un problema de carga de la prueba. Sin embargo, como lo han sugerido Alessandri y Abeliuk, entender dicha clasificación en ese sentido resulta inútil en nuestro país, pues el ordenamiento jurídico tiene resuelto el problema de la carga de la prueba en el artículo 1547 inciso $3^{\circ} \mathrm{CCCh}$., correspondiendo al deudor la prueba de la diligencia ${ }^{10}$.

Esta opinión es válida, en cuanto efectivamente la presunción contra el deudor está recogida en el precepto. Por eso, la utilidad en el ordenamiento jurídico chileno está en entender cuándo existe incumplimiento contractual, pues es diversa la respuesta según se trate de obligaciones de medio o de resultado y es en este sentido que la clasificación debe entenderse, resultando útil para resolver problemas de responsabilidad contractual.

En efecto, lejos de estar la utilidad de la distinción en un simple problema de distribución de carga de la prueba, el real aporte de la distinción es clarificar cuándo existe incumplimiento contractual y la función que debemos asignar a la culpa.

Tanto en las obligaciones de medio como aquellas de resultado el hecho generador de responsabilidad es el incumplimiento. Peñailillo señala que: "Para precisar qué se entiende por incumplimiento, o cuándo se incumple, es para lo que surge la utilidad de la distinción. La de resultado está incumplida cuando el deudor no ha proporcionado al acreedor el resultado al que se comprometió. En la obligación de medio la situación es más compleja. Como principio, la obligación está incumplida cuando el deudor no se ha comportado con la diligencia debida" ${ }^{11}$.

En definitiva, y esto es lo relevante tratándose de obligaciones contrac-

de Derecho y Jurisprudencia 7 (1910), “Doctrina”, p. 253; DucCi Claro, C., La culpa del acreedor en la responsabilidad contractual, en Revista de Derecho y Jurisprudencia 81 (1984), "Doctrina", p. 1.

${ }^{9}$ Demogue, Traité, cit. (n. 6), núm. 1237.

${ }^{10}$ Alessandri Rodríguez, A., De la responsabilidad extracontractual en el derecho civil chileno (Santiago, Universitaria, 1943), p. 53; Abeliuk Manasevich, R., Las obligaciones (Santiago, Editorial Jurídica de Chile, 1993), I, p. 180.

${ }^{11}$ Peñallillo, cit. (n. 2), p. 227. 
tuales que involucran la prestación de una diligencia para su cumplimiento -obligaciones de medios-, el incumplimiento se identifica con la imputación. El mismo Peñailillo lo indica en forma categórica, refiriéndose a la imputabilidad "lo que ocurre es que en las obligaciones de medio este elemento -la culpa- viene a identificarse con el incumplimiento"12.

Asumido que en las obligaciones de diligencia, el incumplimiento se identifica con la culpa, queda pendiente determinar a quién le corresponde la carga de la prueba en consideración a los artículos 1698 y 1547 inciso $3^{\circ} \mathrm{CCCh}$. ante una demanda de indemnización de perjuicios.

\section{LA CARGA DE LA PRUEBA DE LA CULPA POR INCUMPLIMIENTO CONTRACTUAL EN LAS OBLIGACIONES DE MEDIO}

El Código Civil consagró una regla particular relativa a la carga de la prueba de la culpa en materia contractual. El mismo artículo que sirve de asiento a la denominada teoría de prestación de culpas, relativa al deber de diligencia exigible al deudor según la utilidad que reporta el contrato para las partes, señala en forma expresa que "la prueba de la diligencia o cuidado incumbe al que ha debido emplearlo".

Esta regla ha sido interpretada por la doctrina mayoritaria como el refugio de una presunción de culpa contra el deudor contractual ${ }^{13}$. Por consiguiente, al acreedor le basta acreditar la existencia de la obligación contractual y nada más afirmar el incumplimiento para colocar al deudor en situación de aportar la prueba de la ejecución completa y suficiente bajo amenaza de ser declarado responsable. En otros términos, si la ejecución de la obligación contractual exige un comportamiento, cuyo fundamento jurídico o causa eficiente debe acreditar el acreedor, al mismo tiempo que

${ }^{12}$ Ibíd., p. 229.

${ }^{13}$ En este sentido Domínguez Águila, R., La causalité dans la responsabilité en droit comparé francais et chilien (tesis, Universidad de Toulouse, 1967), p. 27; ABEliuk, Manasevich R., cit. (n. 10), II, p. 684; Tapia SuÁrez, O., De la responsabilidad civil en general $y$ de la responsabilidad delictual entre los contratantes (memoria de Prueba, Concepción, 1941), núm. 240; Gatica Pacheco, S., Aspectos de la indemnización de perjuicios por incumplimiento del contrato (Santiago, Editorial Jurídica de Chile, 1959), núms. 40 y 54; Moreno Araya, G., La teoría de la culpa en el Código Civil (memoria de Prueba, Universidad de Chile, Santiago, 1927), núm. 2, p. 3; Ducci Claro, C., Responsabilidad civil (memoria de Prueba, Universidad de Chile, 1936), núm. 9; Rodríguez Grez, P., Responsabilidad extracontractual (Santiago, Editorial Jurídica de Chile, 1999), p. 23; cf. AlesSANDri Rodríguez, A., cit. (n. 10), núm. 27, p. 52, en particular la nota 2; VELASCO, X., La responsabilidad contractual por el hecho ajeno (memoria de Prueba, Universidad de Chile, Santiago, Universitaria, 1962), p. 29. 
debe aseverar que hubo un incumplimiento; la prueba de la diligencia o cumplimiento de la obligación pertenece al deudor.

Las raíces históricas de la presunción de culpa contra el deudor se encuentran en la opinión común de la doctrina francesa hasta principios del siglo $\mathrm{XX}^{14}$. En efecto, desde la emisión del Código Civil francés, la doctrina se esforzó en entender la referida contradicción entre los artículos 1137 y 1147, elaborando distintas interpretaciones para una armonía del régimen de incumplimiento contractual.

En mi opinión, estas discusiones, que conoció Bello, lo motivaron a clarificar en una sola norma el problema de la carga de la prueba en las obligaciones contractuales introduciendo el inciso $3^{\circ}$ del ya citado artículo 1547 CCCh. ${ }^{15}$.

Por lo mismo, la doctrina chilena, como se indicó, reconoce en forma unánime la existencia de una presunción de culpa contra el deudor. El profesor Domínguez Águila señala que : "la culpa en materia contractual se presume. Corresponderá al deudor probar, ya sea que el incumplimiento del contrato se debe a caso fortuito o a otra causa extraña o que no es responsable del incumplimiento al haber empleado toda la diligencia que le era exigible" 16 .

Por su parte, Alessandri Rodríguez, en forma más categórica sostuvo que "tratándose de la responsabilidad contractual, el acreedor debe sólo probar la existencia de la obligación, y no tiene necesidad de probar que el incumplimiento proviene de la culpa del deudor; ésta queda demostrada por el solo hecho del incumplimiento" 17 .

Es decir, al acreedor le basta la prueba de la existencia de la obligación, quedando de cargo del deudor excluir la concurrencia del incumplimiento culpable.

Se trata de la interpretación clásica de la doctrina francesa desde mediados del siglo XX. Los hermanos Mazeaud afirmaron que "es preferible siguiendo a eminentes autores decir que la culpa está probada, realizada.

${ }^{14}$ La doctrina propuso una distribución según la naturaleza positiva o negativa de la prestación contractual. Véase: GRANDMOULIn, J., De l'unité de la responsabilité ou nature délictuelle de la responsabilité pour violation des obligations contractuelles (Paris, 1882), p. 55 ; M. Planiol, nota DP. (1896), 21, p. 457; Huc, T., Commentaire du Code Civil (Paris, F. Pichon, 1892), VII, núm. 95 ; LabBé, E., nota S. (1886), 4.25.

${ }^{15}$ Sobre esto con mayor profundidad, mi tesis doctoral citada en nota 6 , in fine. Ahí pretendo mostrar las razones de Bello para alterar la carga de la prueba en forma definitiva a favor del acreedor, citando a los autores franceses que sembraron la incertidumbre sobre una cuestión esencial de la responsabilidad contractual.

${ }^{16}$ Domínguez, R., cit. (n. 13), p. 27.

${ }^{17}$ Alessandri, A., cit. (n. 10), núm. 27, p. 52. 
El incumplimiento de una obligación contractual constituye una culpa ya realizada y probada" ${ }^{18}$.

En Chile, quien ha tratado en forma más clara este problema: la relación del incumplimiento con la culpa y la carga de la prueba, es el profesor Daniel Peñailillo. Para este autor, respecto a la prueba del incumplimiento deben tenerse en cuenta los artículos 1698 y 1547 inciso $3^{\circ}$ CCCh.

En conformidad al artículo 1698 la existencia de la obligación debe ser probada por quien la alega y, lo mismo ocurre respecto al incumplimiento: la carga de la prueba está en quien lo reclama. La otra premisa que indica el mismo autor es que el cumplimiento (ejecución de la prestación, pago) constituye una causal de extinción de la obligación: "con lo cual, técnicamente, la prueba del cumplimiento cae en la segunda parte de la regla probatoria del art. 1698; el cumplimiento (extinción) de la obligación debe ser probado por el que lo alega"19. Y concluye: "En la obligación de medio, si el acreedor alega que el deudor fue negligente (que incumplió) y el deudor alega que fue diligente (que cumplió), es el deudor el que debe probar que fue diligente, porque está alegando que extinguió (por cumplimiento) su obligación de comportarse diligentemente (sin importar que un resultado esperado no se haya producido).

En la obligación de resultado, si el acreedor alega que el resultado no se produjo (que el deudor incumplió) y el deudor alega que el resultado se produjo (que cumplió), es el deudor el que debe probar que el resultado se produjo, en los términos en los que se convino, porque está alegando que extinguió (por cumplimiento) su obligación de obtener el resultado.

En suma, en ambos casos es el deudor quien tiene el peso de la prueba; sólo que el contenido de la prueba es distinto" 20 .

El profesor Peñailillo acierta al considerar que basta el artículo 1698 para resolver la carga de la prueba en materia de responsabilidad contractual. Corresponde al deudor que pretende extinguir su obligación acreditar el cumplimiento, ya sea una obligación de medio o de resultado. La razón es simple, la prueba del cumplimiento de la obligación -diligencia exigida o promotora del cumplimiento- equivale a la extinción de la obligación.

La correcta interpretación del artículo 1698 distribuye la carga de la prueba respecto a las obligaciones distinguiendo la fuente de la misma (existencia) y su extinción (pago de las mismas). Efectivamente corresponde al acreedor acreditar la existencia de la obligación. El acreedor demandante debe probar la existencia del contrato. En otros términos le corresponde

${ }^{18}$ Mazeaud, H. - L. y Tunc, A., Traité théorique et pratique de la responsabilité civile délictuelle et contractuelle (Paris, Montchrestien, 1965), I, núm. 696-2.

${ }^{19}$ Peñailillo, cit. (n. 2), p. 228.

${ }^{20}$ Ibíd., p. 229. 
la prueba de la causa eficiente: la obligación contractual que se pretende incumplida. Por el contrario, una vez acreditada la obligación, es al deudor, en conformidad al mismo precepto, que le corresponde probar su extinción. Y la forma de acreditar la extinción de la obligación no es más que el cumplimiento de la misma.

No puede, tratándose de una obligación de medios, disociarse el incumplimiento de la culpa en las obligaciones de medios. Como se ha indicado es una certidumbre que el artículo 1547 inciso $3^{\circ} \mathrm{CCCh}$. contempla una presunción de culpa, en el entendido que corresponde al deudor probar la diligencia para exonerarse de responsabilidad. Fuera de la hipótesis de fuerza mayor o caso fortuito, el deudor sólo puede liberarse de responsabilidad probando que fue diligente.

Como se indicó, tratándose de obligaciones de medio o promotora del cumplimiento, el deudor queda obligado a ejecutar su obligación con la diligencia de un buen padre de familia en los contratos bilaterales.

Es decir, en presencia de obligaciones contractuales de diligencia no es posible diferenciar el cumplimiento de la diligencia debida o, lo que es lo mismo, el incumplimiento de la culpa. Incumple el deudor que actuó con culpa al no emplear la diligencia debida. En materia de responsabilidad contractual, el incumplimiento constituye culpa, siendo imposible disociar ambos elementos en atención a la noción de incumplimiento de aquellas obligaciones que involucrar exigencia de diligencia para la satisfacción del acreedor. Entenderlo de otra manera infringe el artículo 1547 inciso $3^{\circ} \mathrm{CCCh}$.

En cambio, tratándose de obligaciones de resultado, la culpa carece de función, siendo sólo relevante si la obligación fue satisfecha o no, excluyéndose un análisis del comportamiento del deudor destinado a lograr la satisfacción de la pretensión. En otros términos, al calificar la obligación contractual como de resultado, se instaura una genuina responsabilidad objetiva en sede contractual. El problema que esta aseveración involucra estriba en lograr darle base legal a esta interpretación. Un óbice importante lo constituye la propia regla del artículo 1547 CCCh. que al instaurar la teoría de la prestación de culpa erige a ésta como un elemento de la indemnización de perjuicios. Sin embargo, dos alternativas pueden esgrimirse para la introducción de las obligaciones de resultado. Por una parte, aceptar una culpa contra la legalidad en materia de incumplimiento contractual o, quizá la opción más apropiada, darle una interpretación al artículo 1557 CCCh. en clave objetiva que excluya la culpa como un elemento de la responsabilidad contractual.

En definitiva, debe concluirse que en las obligaciones de medios o de diligencia el incumplimiento involucra la culpa del deudor, siendo 
imposible disociar ambos conceptos. Esto implica, en conformidad a los artículos 1547 inciso $3^{\circ}$ y 1698 CCCh., que corresponde al acreedor probar la causa eficiente de la obligación, o lo que es lo mismo, su existencia; y, en cambio, es carga del deudor acreditar la ejecución correcta de la obligación o la diligencia esperada, en conformidad a la correcta interpretación de los artículos 1547 inciso $3^{\circ}$ y 1698 CCCh.

[Recibido el 29 de octubre y aceptado el 15 de noviembre de 2008].

\section{BIBLIOGRAFÍA}

Abeliuk Manasevich, R., Las obligaciones (Santiago, Editorial Jurídica de Chile, 1993).

Alessandri Rodríguez, A., De la responsabilidad extracontractual en el derecho civil chileno (Santiago, Universitaria, 1943).

Barros Bourie, E., Finalidad y alcance de las acciones y los remedios contractuales, en GuZMÁn Brito, Alejandro (editor científico), Estudios de Derecho Civil III (Santiago, LegalPublishing, 2008).

Barros Bourie, E., La diferencia entre estar obligado y ser responsable en el derecho de los contratos, en VARAS BRAUn, Juan Andrés - TuRner SAELZER, Susan (coordinadores), Estudios de Derecho Civil (Santiago, LexisNexis, 2006).

BeInEX, R., La charge de la preuve de l'exécution en matière contractuelle, en Revue Crititique (1938).

Bigot-Préameneu, F. J., Présentation au corps législatif et exposé des motifs du titre des contrats, en FENET, Récueil (Paris, 1829), XIII.

Claro Solar, L., Ligeras observaciones sobre la prestación de la culpa en el contrato de mandato, en Revista de Derecho y Jurisprudencia 7 (1910), "Doctrina”, p. 253.

Demogue, R., Traité des obligations (Paris, Arthur Rousseau, 1923-1933), V.

Díez-Picazo, L., Fundamentos de Derecho civil patrimonial. Introducción. Teoría general del contrato y las relaciones obligatorias (Madrid, Civitas, 1996), I-II.

Domínguez Águila, R., La causalité dans la responsabilité en droit comparé francais et chilien (tesis, Universidad de Toulouse, 1967).

Ducci Claro, C., La culpa del acreedor en la responsabilidad contractual, en Revista de Derecho y Jurisprudencia 81 (1984), "Doctrina”.

Ducci Claro, C., Responsabilidad civil (memoria de Prueba, Universidad de Chile, 1936).

Esmein, P., Le fondement de la responsabilité contractuelle, en Revue trimestrelle de Droit Civil (1933).

EsmeIn, P., Remarques sur les nouvelles classifications des obligations, en Mélanges Capitant (Paris, Dalloz, 1939), p. 235.

Frossard, J., La distinction des obligations de moyens et des obligations de résultats ("Préface" de R. Nerson, Paris, LGDJ, 1965).

Gatica Pacheco, S., Aspectos de la indemnización de perjuicios por incumplimiento del contrato (Santiago, Editorial Jurídica de Chile, 1959).

Grandmoulin, J., De l'unité de la responsabilité ou nature délictuelle de la responsabilité pour violation des obligations contractuelles (Paris, 1882).

Huc, T., Commentaire du Code civil (Paris, F. Pichon, 1892), VII. 
Larroumet, Ch., Droit civil, Les obligations (Paris, Economica, 1998).

Mazeaud, H.-L. y Tunc, A., Traité théorique et pratique de la responsabilité civile délictuelle et contractuelle (Paris, Montchrestien, 1965).

Mazeaud, H., Essai de classification des obligations, en Revue trimestrelle de Droit Civil (1936).

Moreno Araya, G., La teoría de la culpa en el Código Civil (memoria de Prueba, Universidad de Chile, Santiago, 1927).

Morton, G., Obligations de résultat et obligations de moyens, en Revue Trimestrelle de Droit Civil (1935).

Peñailillo Arévalo, Daniel, Las obligaciones. Teoría general y clasificaciones. La resolución por incumplimiento (Santiago, Editorial Jurídica de Chile, 2003).

Pizarro Wilson, C., Étude critique de la responsabilicé contractuelle en Droit positif chilien (tesis, Paris II, 2003).

Pizarro Wilson, C., Hacia un sistema de remedios al incumplimiento contractual, en GuZmán Brito, Alejandro (editor científico), Estudios de Derecho Civil III (Santiago, LegalPublishing, 2008).

Pizarro Wilson, C., La responsabilidad contractual en Derecho civil chileno, en ManTILLA, Fabricio (coordinador), Libro colectivo. Problemas de Derecho de los contratos (Bogotá, Legis, 2007).

Pothier, R., Traité des obligations, en Euvres de Pothier por M. Bugnet (Paris, 1861), II.

Rémy, Ph., La responsabilicé contractuelle. Histoire d'un faux concept, en Revue Trimestrelle de Droit Civil (1997).

Rodière, R., Etudes sur la dualité des régimes de responsabilicé, en Juris Classeur. "Doctrine" (1950).

Rodríguez Grez, P., Responsabilidad extracontractual (Santiago, Editorial Jurídica de Chile, 1999).

TAPIA SuÁrez, O., De la responsabilidad civil en general y de la responsabilidad delictual entre los contratantes (memoria de Prueba, Concepción, 1941).

Terré, F., Simler, Ph. et Lequette, Y., Les obligations (Paris, Dalloz,1996).

Thomas, C., La distinction des obligations de moyen et des obligations de résultat, en Revue Trimestrelle de Droit Civil (1937).

Tunc, A., La distinction des obligations de résultat et des obligations de diligence, en Juris Classeur. "Doctrine" (1945).

VelasCo, X., La responsabilidad contractual por el hecho ajeno (memoria de Prueba, Universidad de Chile, Santiago, Universitaria, 1962).

VIDal Olivares, A., El incumplimiento de obligaciones con objeto fungible y los remedios del acreedor afectado. Una relectura de las disposiciones del Código civil sobre incumplimiento, en GuZMán Brito, Alejandro (editor científico), El Código Civil de Chile (1855-2005) (Santiago, LexisNexis, 2007).

VIDAL Olivares, A., La pretensión de cumplimiento especifico y su inserción en el sistema de remedios por incumplimiento en el Código Civil, en CORRAL, Hernán- RodríguEz, María Sara (coordinadores), Estudios de Derecho Civil II (Santiago, LexisNexis, 2006).

Vidal Olivares, A., La protección del comprador. Régimen de la Convención de Viena y su contraste con el Código Civil (Valparaíso, Ediciones Universitarias, 2006). 
